\title{
BMJ Open Maternal alcohol disorders and school achievement: a population cohort record linkage study in Western Australia
}

\author{
Sarah E Johnson, ${ }^{1}$ Colleen O'Leary, ${ }^{2}$ Carol Bower, ${ }^{1}$ David Lawrence, ${ }^{1,3}$ \\ Nadia Cunningham, ${ }^{1,4}$ James Semmens, ${ }^{5}$ Stephen R Zubrick ${ }^{1,3}$
}

To cite: Johnson SE, O'Leary C, Bower $\mathrm{C}$, et al. Maternal alcohol disorders and school achievement: a population cohort record linkage study in Western Australia. BMJ Open 2017;7:e014599. doi:10.1136/ bmjopen-2016-014599

- Prepublication history and additional material are available. To view these files please visit the journal online (http://dx.doi.org/ 10.1136/ bmjopen-2016-014599).

Received 6 0ctober 2016 Revised 4 March 2017 Accepted 23 March 2017

\section{(a) CrossMark}

${ }^{1}$ Telethon Kids Institute, The University of Western Australia, Perth, Australia

${ }^{2}$ Department of Health, Office of the Chief Psychiatrist, East Perth, Australia

${ }^{3}$ Graduate School of Education, The University of Western Australia, Perth, Australia

${ }^{4}$ School of Psychology, The University of Western Australia, Perth, Australia

${ }^{5}$ Centre for Population Health Research, Faculty of Health Sciences, Curtin University, Perth, Australia

\section{Correspondence to}

Dr. Sarah E Johnson;

Sarah.Johnson@telethonkids. org.au

\section{ABSTRACT}

Objective Maternal alcohol use disorder is a risk factor for a range of developmental outcomes in children. This study examines school achievement in children of Indigenous and non-Indigenous mothers with an alcohol-related diagnosis.

Design, setting and participants This is a Western Australian population cohort study of mothers with a record of an alcohol-related diagnosis classified by the International Classification of Diseases Revisions 9/10 codes as recorded on administrative databases, and of their offspring born between 1989 and 2007 ( $n=18486$ exposed children), with a frequency matched comparison cohort of mothers with no record of alcohol diagnosis and their offspring ( $n=48262$ comparison children).

Outcomes Records were linked with school achievement data for numeracy and literacy from Years 3, 5, 7 and 9 (age range: $~ 8-14$ years) based on statewide and national testing. Mixed multivariate models with a random intercept per child were used to assess the relationship between exposure and the timing of exposure with failure to meet minimum standardised benchmarks.

Results Academic achievement was lower in all testing domains (reading, writing, spelling and numeracy) among children of mothers with an alcohol diagnosis and persisted across all year groups examined. The highest ORs at Year 9 for non-Indigenous children were in reading (adjusted OR (aOR) 1.6, 95\% Cl 1.4 to 1.8) and in writing for Indigenous children (aOR 2.0,95\% $\mathrm{Cl} 1.8$ to 2.3).

Conclusion Children of mothers with alcohol use disorders are at risk of not meeting minimum educational benchmarks in numeracy and literacy, with the risk highest among Indigenous children.

\section{INTRODUCTION}

Improving educational achievement among disadvantaged children is a national priority in Australia. ${ }^{1}$ Between $6 \%$ and $8 \%$ of Australian children do not achieve national minimum standards for reading and numeracy, with proportions around fourfold higher for Indigenous students. ${ }^{2}$ School performance is influenced by a child's early development and school readiness, which are shaped by community, social, family and parental/carer factors such as education and health behaviours. ${ }^{34}$

\section{Strengths and limitations of this study}

A major strength of this study is the use of a population-based cohort of non-Indigenous and Indigenous mothers with a matched comparison cohort.

- The exposed cohort (having an alcohol diagnosis) was identified based on standard International Classification of Diseases Revisions 9/10 codes.

- The educational outcomes are standardised measures and comparable with national and state benchmark data.

- Loss to follow-up is unavoidable- $71.1 \%$ of the birth cohort linked to an achievement record partly because data were limited to public schools. Participation rates were also lower in the exposed versus the comparison cohorts.

- Another limitation is the definition of the cohortthese are serious alcohol use disorders and there will be women in the comparison cohort who may use alcohol at high levels.

Children of mothers with alcohol use disorders are placed at risk prenatally and through exposure to numerous environmental and psychological risk factors postnatally. Heavy prenatal alcohol exposure, in particular a binge pattern of exposure, increases the risk of a range of neurodevelopmental problems, termed fetal alcohol spectrum disorders (FAS)..$^{5-7}$ Environmental risks include parental mental health problems, poor parenting skills and low supervision, family disruption and conflict, family mobility, and social isolation. ${ }^{8}$ Cognitive, behavioural, emotional, social and other neuropsychological deficits are all mechanisms through which prenatal ${ }^{510}$ and environmental ${ }^{89}$ exposure to maternal alcohol disorders could lead to poorer academic outcomes.

Studies examining the impact of prenatal alcohol exposure on school achievement by various measures, including psychometric assessments, ${ }^{11-17}$ parent/self-rated assessments, ${ }^{12}$ teacher-rated assessments ${ }^{12}$ and 
standardised school-based assessments, ${ }^{14}{ }^{18-22}$ have found that the most consistent negative association was in respect of the impact of binge drinking. Findings are mixed as to whether particular domains of learning are more strongly disrupted. In the Seattle Longitudinal Study on Alcohol and Pregnancy (offspring of mothers oversampled for heavier drinking and smoking), the most consistent effect of prenatal binge drinking was in respect to lower performance on arithmetic tests as reported at ages 7, 11 and 14, although the effects were seen in other learning domains. ${ }^{14-17}$ In studies by Goldschmidt and colleagues based on a low-income cohort, deficits were found in mathematics, reading and spelling ability at age $6^{11}{ }^{12}$ but not in mathematics at age $10 .{ }^{12}$ Howell et al found effects on standardised tests in mathematics but not reading or spelling at age $15 .{ }^{19}$ In contrast, in a Western Australian (WA) study, O'Leary et al only found effects for binge drinking in the first trimester on the reading test but not on numeracy, writing or spelling at age $8-9$ years. ${ }^{20}$ Studies based on the Avon Longitudinal Study of Parents and Children have linked maternal binge drinking with lower overall performance on national standardised tests among 10 to 11-year-olds. ${ }^{18}{ }^{21}$ Variations between learning domains may be accounted for by methodological differences in existing studies.

This study uses routinely collected linked population-based health and education data to examine the school achievement of children of mothers who have an alcohol-related diagnosis, which is a proxy for maternal alcohol use disorder. This study overcomes problems associated with recruiting and retaining mothers with a diagnosed alcohol use disorder and their children in longitudinal studies, ${ }^{10} 23$ and addresses many of the methodological limitations of previous studies such as classification of alcohol consumption, lack of a comparison cohort, sample bias and inconsistent adjustment for known confounders. ${ }^{6}$ It was hypothesised that children of mothers with an alcohol-related diagnosis would have a significantly higher risk of failing to reach minimum education benchmarks in numeracy and literacy.

\section{METHODS}

\section{Study design}

This is a cohort study using linked population administrative data. The original birth cohort has previously been described. ${ }^{24}$ All women with a birth recorded on the WA Midwives Notification System (MNS) between 1983 and 2007 were in scope. Mothers (and their offspring) are classified as being Indigenous if they have at least one record on the MNS of being either of Australian Aboriginal or Torres Strait Islander descent. Figure 1 shows how the study cohorts were selected for this paper.

Ethics approval for the conduct of the study was granted by the Princess Margaret Hospital Human Research Ethics Committee (No. 1244/EP), the WA Department of Health Human Research Ethics Committee
(No. 2011/34) and the WA Aboriginal Health Ethics Committee (No. 134-04/06).

\section{Cohort selection (exposed and comparison cohorts)}

The exposed cohort comprised women who gave birth in WA between 1983 and 2007, and had an alcohol-related diagnosis according to the International Classification of Diseases Revisions 9/10 (ICD-9 or ICD-10) from the medical records coded by trained coders. The diagnosis was identified through routinely collected administrative data, including the Hospital Morbidity Data System (HMDS/hospital inpatients), mental health outpatients and the Perth-based Drug and Alcohol Office. The ICD-9 and/or ICD-10 codes included alcohol-related mental and behavioural disorders, an alcohol-related disease with $100 \%$ attributable fraction and other alcohol codes (see online supplementary table 1). ${ }^{24}$ There were 8519 mothers with an alcohol-related diagnosis and 18486 births to these mothers between 1989 and 2007.

The comparison cohort consisted of a random selection of mothers with a birth recorded on the MNS without an alcohol-related diagnosis recorded on any of the data sets. The comparison cohort was frequency-matched to the exposed cohort on maternal age within maternal race and year of birth of her child. The ratio of comparison to exposed cohorts was 3:1 for non-Indigenous children and 2:1 for Indigenous children. There were 38490 comparison mothers and 48262 comparison births between 1989 and 2007.

\section{Measures}

Exposure variable (maternal alcohol use diagnosis)

Exposure was examined as (1) a binary variable (yes/no) and (2) the timing of recording of alcohol-related diagnosis in relation to pregnancy using a hierarchical coding as previously described. ${ }^{24}$ Being classified as having a diagnosis during pregnancy did not exclude a diagnosis from also being recorded before or after pregnancy.

\section{School achievement data}

School achievement data came from the Western Australian Literacy and Numeracy Assessment (WALNA) for assessment years 1999-2007 and the National Assessment Program - Literacy and Numeracy (NAPLAN) tests for assessment years 2008-2011. WALNA was a statewide testing programme in numeracy, writing, reading and spelling undertaken by all students in Years 3, 5 and 7 (average age 8, 10 and 12, respectively). From 2005 to 2007 , numeracy, reading and writing were also assessed in Year 9. Benchmarks for minimum standards of performance in WALNA tests were provided by the WA Department of Education.

NAPLAN is a national testing programme that has been administered annually since 1998 to all students in Years $3,5,7$ and 9 (average age 8.5, 10.5, 12.5 and 14.5 years, respectively). NAPLAN provides a single scale of achievement across 10 bands from Years 3-9 in aspects of reading, writing, language conventions (spelling and grammar) 


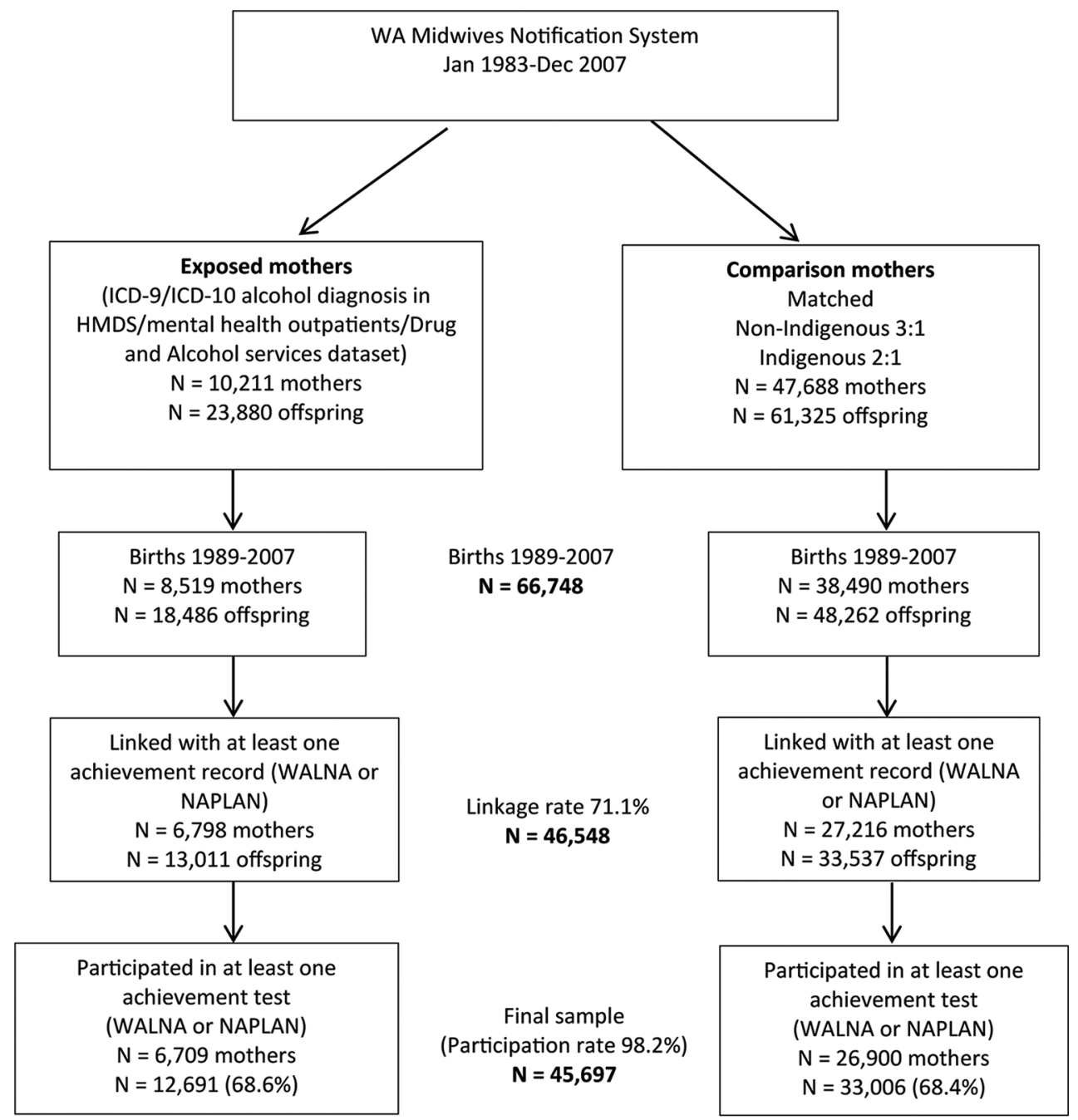

Figure 1 Flow chart of cohort selection and numbers participating in study. HMDS, Hospital Morbidity Data System; ICD, International Classification of Diseases; NAPLAN, National Assessment Program - Literacy and Numeracy; WA, Western Australia; WALNA, Western Australian Literacy and Numeracy Assessment.

and numeracy. Scoring in band 1 in Year 3, bands 1-3 in Year 5, bands 1-4 in Year 7 and bands 1-5 in Year 9, or being exempt (eg, students with language background other than English or a disability), was classified as not meeting the benchmark for national minimum standards. $^{25}$

The birth cohort data were linked with the WA Department of Education data (public schools only) by the WA Data Linkage Unit using probabilistic matching techniques. ${ }^{26}$ Data were successfully linked to at least one achievement record for $71.1 \%$ of children. Participation in WALNA and NAPLAN testing was higher in non-Indigenous students compared with Indigenous students, and lower among children of mothers with an alcohol diagnosis than children in the comparison cohort (table 1). The relative difference in participation between children of mothers with an alcohol diagnosis and those of comparison mothers was higher among Indigenous students (range: 3.1\%-8.6\% compared with 1.2\%-2.6\% among non-Indigenous students).
Participation was lowest for Indigenous children of mothers with an alcohol diagnosis during NAPLAN testing (74.2\%-77.8\%).

Overall, 45697 children had participated in at least one test in the follow-up period. WALNA and NAPLAN test results were combined with a maximum of four test results per child (a maximum of four for WALNA and four for NAPLAN). When combined, 9173 students had one test result, 12167 had two test results, $10771 \mathrm{had}$ three test results and 13586 had four test results. There were 7804 exposed non-Indigenous children and 4887 exposed Indigenous children in the exposed cohort.

Three times the proportion of Indigenous mothers (2.6\%) compared with non-Indigenous mothers $(0.8 \%)$ had an alcohol diagnosis record during pregnancy. The proportions of non-Indigenous and Indigenous mothers with an alcohol diagnosis 'greater than 1 year prepregnancy' were $6.4 \%$ and $5.2 \%$, 'up to 1 year prepregnancy' were $1.7 \%$ and $2.2 \%$, 'up to 1 year postpregnancy' were $0.9 \%$ and $1.7 \%$, and 'greater than 
Table 1 Proportion of children participating in the WALNA and NAPLAN testing in Years 3, 5, 7 and 9 by Indigenous status and cohort

\begin{tabular}{lllll}
\hline & \multicolumn{2}{l}{ Non-Indigenous } & Indigenous & \\
\cline { 2 - 5 } Testing domain & Exposed (\%) & Comparison (\%) & Exposed (\%) & Comparison (\%) \\
\hline WALNA 1999-2007 & 96.6 & 97.8 & 90.3 & 93.4 \\
Numeracy & 95.4 & 97.2 & 83.6 & 89.6 \\
Reading & 94.7 & 96.4 & 80.3 & 86.6 \\
Writing & 96.5 & 97.8 & 85.4 & 91.1 \\
Spelling & & & 74.2 & 82.3 \\
NAPLAN 2008-2011 & 93.6 & 96.2 & 75.2 & 83.8 \\
Numeracy & 94.1 & 96.5 & 76.2 & 84.3 \\
Reading & 94.4 & 96.5 & 77.8 & 85.2 \\
\hline Writing & 94.6 & 96.7 & & \\
\hline Language conventions & & & & \\
\hline
\end{tabular}

Notes: In WALNA testing, participation is estimated as the proportion who took the test over the total number of eligible students (either participated or absent). In NAPLAN testing, participation was estimated as the proportion of all assessed or exempt students over the total number of eligible students, including those who were absent or withdrawn. In NAPLAN testing, exempt students (who may have significant intellectual disability or a language background other than English) are classified as being below national minimum standard. Parents can apply to withdraw their child from NAPLAN testing on the basis of religious beliefs or philosophical objections.

NAPLAN, National Assessment Program - Literacy and Numeracy; WALNA, Western Australian Literacy and Numeracy Assessment.

1 year postpregnancy' were $16.2 \%$ and $19.3 \%$, respectively.

\section{Confounding variables}

Child factors included were gender, preterm birth (born $<37$ weeks' gestation) and low birth weight $(<2500$ g). Maternal factors included were parity and marital status, WA health region, and the Australian Bureau of Statistics Socio-Economic Index for Areas (SEIFA), both based on postcode of residential address at the time of the birth. Analyses were further adjusted for maternal mental health diagnosis (ICD-9/ICD-10 codes on the HMDS or the mental health outpatient data) and maternal record of illicit drug diagnosis recorded on either the HMDS, mental health outpatients and/or the Drug and Alcohol data set. Smoking status during pregnancy was available on the MNS from 1998.

\section{Analysis}

All analyses were run separately for non-Indigenous and Indigenous children. The frequency matching variables and all confounders were included on the basis of significance in univariate testing. Missing data for SEIFA were included as categories, whereas cases with missing data for marital status and birth weight were dropped in modelling. The significance of differences in the distribution of maternal and child characteristics between those with a maternal alcohol diagnosis and those without was determined using a $\chi^{2}$ test.

Initially, the relationship between maternal alcohol-related diagnosis and failure to attain WALNA and NAPLAN benchmarks for each domain was assessed with conditional logistic regression using PROC LOGISTIC in SAS V.9.4.
The combined benchmark data were then modelled using the GLIMMIX procedure in SAS with a random intercept per child. As there were siblings included, we also tested a nested random effect of child within family, but this made no difference to the results. First, an interaction was modelled between exposure and testing year to produce estimates for the exposed versus comparison cohorts in each testing year. Second, the effect of the timing of maternal alcohol-related diagnosis on achieving benchmarks was tested. The significance of the difference in adjusted OR (aOR) between non-Indigenous and Indigenous groups was determined by calculating CIs for the difference between estimates. The predicted probabilities reported in figure 2A-D have been computed using the LSMEANS statement in PROC GLIMMIX for ethnicity by maternal alcohol exposure by year of testing. These values represent the predicted probability of not meeting the benchmark by Indigenous status and alcohol exposure while using the average value across the cohort for all other variables in the model. As such these marginal probabilities model the average probabilities in the specified groups.

Sensitivity analysis was conducted to determine whether adjustment for smoking status altered the findings for the years in which smoking status was available (1998 onwards). This meant restricting the analysis to NAPLAN tests only for years 3,5 and 7 .

\section{RESULTS}

\section{Maternal and child characteristics}

A higher proportion of mothers with an alcohol diagnosis than comparison mothers were never married $(\mathrm{p}<0.001)$ (table 2). Among non-Indigenous mothers, higher 


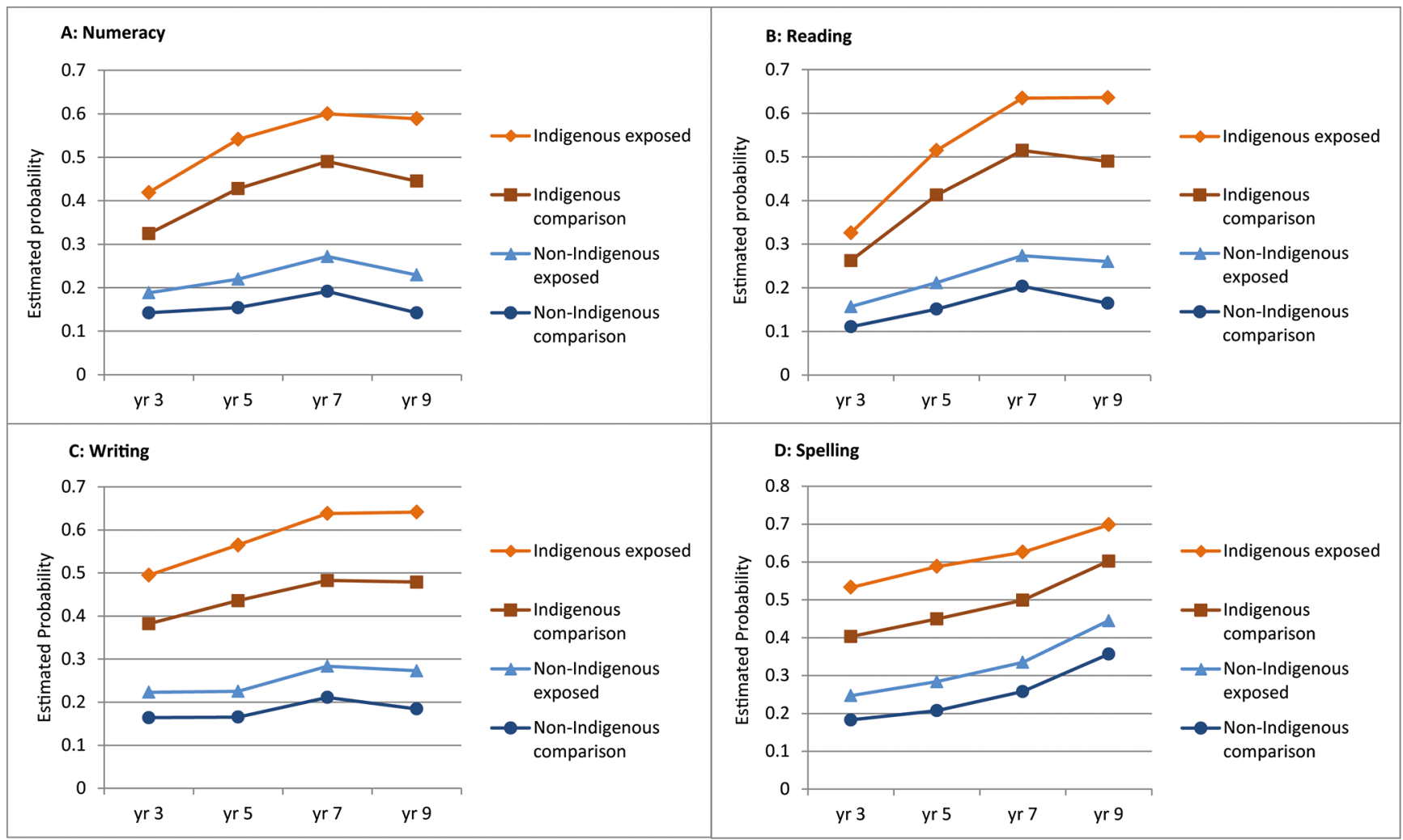

Figure 2 Predicted probability of children not reaching benchmarks in numeracy, reading, writing and spelling among exposed versus comparison children by Indigenous status and testing domain.

proportions of mothers with an alcohol diagnosis lived in more disadvantaged areas compared with comparison mothers, which was not the case for Indigenous mothers. There was, however, a higher proportion of Indigenous mothers with an alcohol diagnosis with missing information for SEIFA. A higher proportion of mothers with an alcohol diagnosis had a record of illicit drug diagnosis, mental disorder diagnosis and maternal smoking during pregnancy than comparison mothers (all contrasts significant at $\mathrm{p}<0.001)$. Mothers with an alcohol diagnosis had a higher parity than comparison mothers, and a higher proportion of their births were low birth weight and preterm (all contrasts significant at $\mathrm{p}<0.001$ ).

\section{Educational benchmarks by testing year}

For all tests the proportion of children failing to meet benchmarks was higher in the exposed than comparison cohorts (table 3). Proportions not meeting benchmarks were higher for Indigenous than non-Indigenous children in both cohorts. Before adjustment for confounding, the odds of failing to achieve the benchmarks were similar for both non-Indigenous and Indigenous children of mothers with an alcohol diagnosis and indicated an increased likelihood of failure ranging between 1.5 and 2.3 times higher than comparison children. After adjustment for confounders, children of mothers with an alcohol diagnosis had greater odds of failing to reaching benchmark status than comparison children (table 4). The ORs of not meeting benchmarks in the exposed cohort ranged from 1.2 to 1.6 among non-Indigenous children and from 1.4 to 2.0 among Indigenous children. The highest ORs at Year 9 for non-Indigenous children were in reading (aOR 1.6, 95\% CI 1.4 to 1.8) and in writing for Indigenous children (aOR 2.0, 95\% CI 1.8 to 2.3). The odds of failing to meet benchmarks in exposed versus comparison cohorts were significantly higher among Indigenous children than non-Indigenous children at all testing years for writing, at Years 3, 5 and 7 for numeracy and spelling, and at Year 7 for reading.

Figure 2A-D displays the predicted probabilities of not meeting benchmarks by Indigenous status and diagnostic status. Overall it can be seen that the difference in estimated probabilities of not reaching benchmarks between children of mothers with an alcohol diagnosis and those in the comparison cohort was larger for Indigenous children than non-Indigenous children. There was a general pattern of increasing probability of not reaching benchmarks from Year 3 through to Year 7, with no increased risk at Year 9, a pattern more pronounced in the Indigenous exposed and comparison cohorts. The exception was for spelling where the risk increased further at Year 9 for Indigenous and non-Indigenous children regardless of exposure.

\section{Educational benchmarks by timing of exposure}

There was no consistent pattern in terms of strength of association between diagnostic status and failure to reach benchmarks by the timing of the record of 


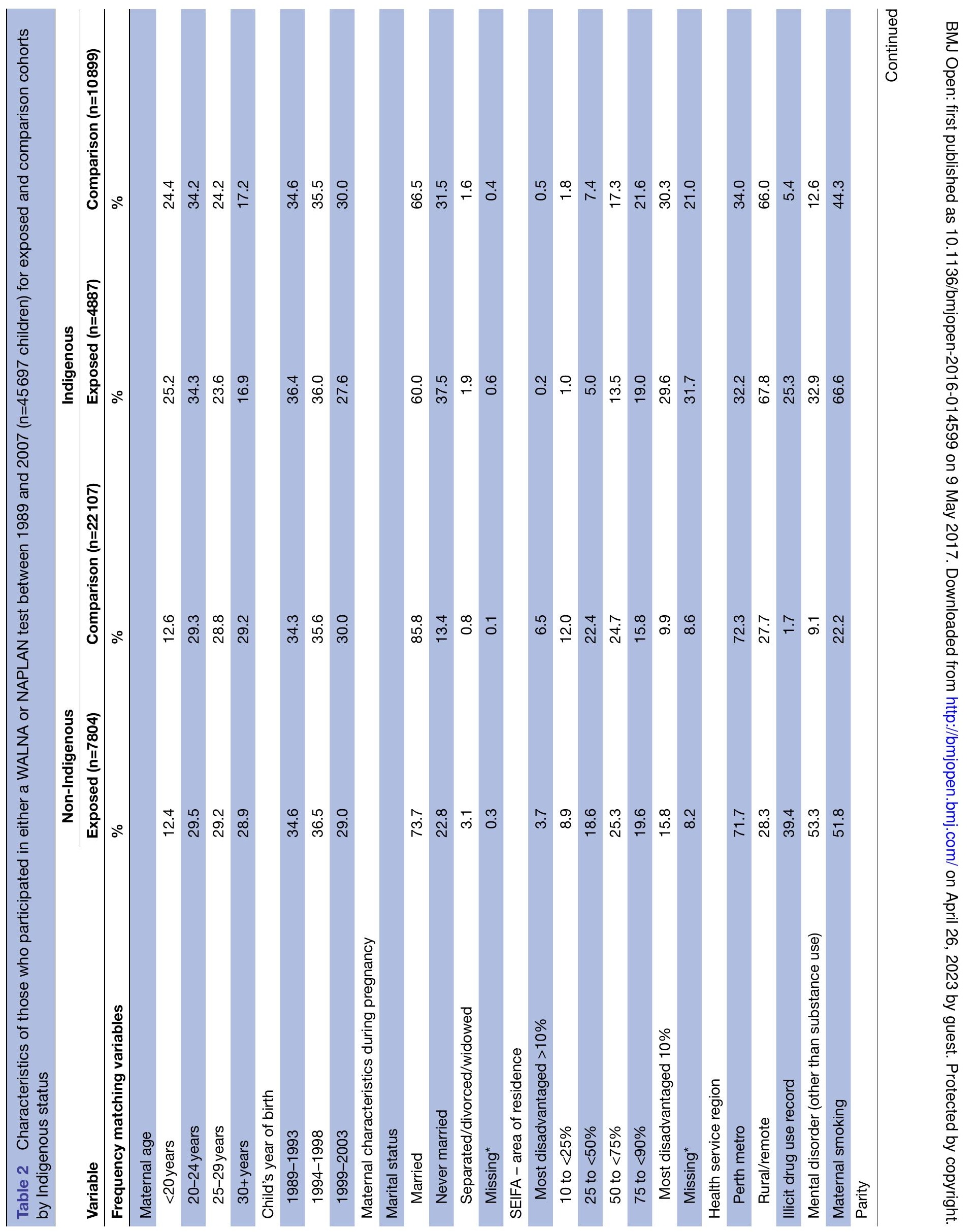




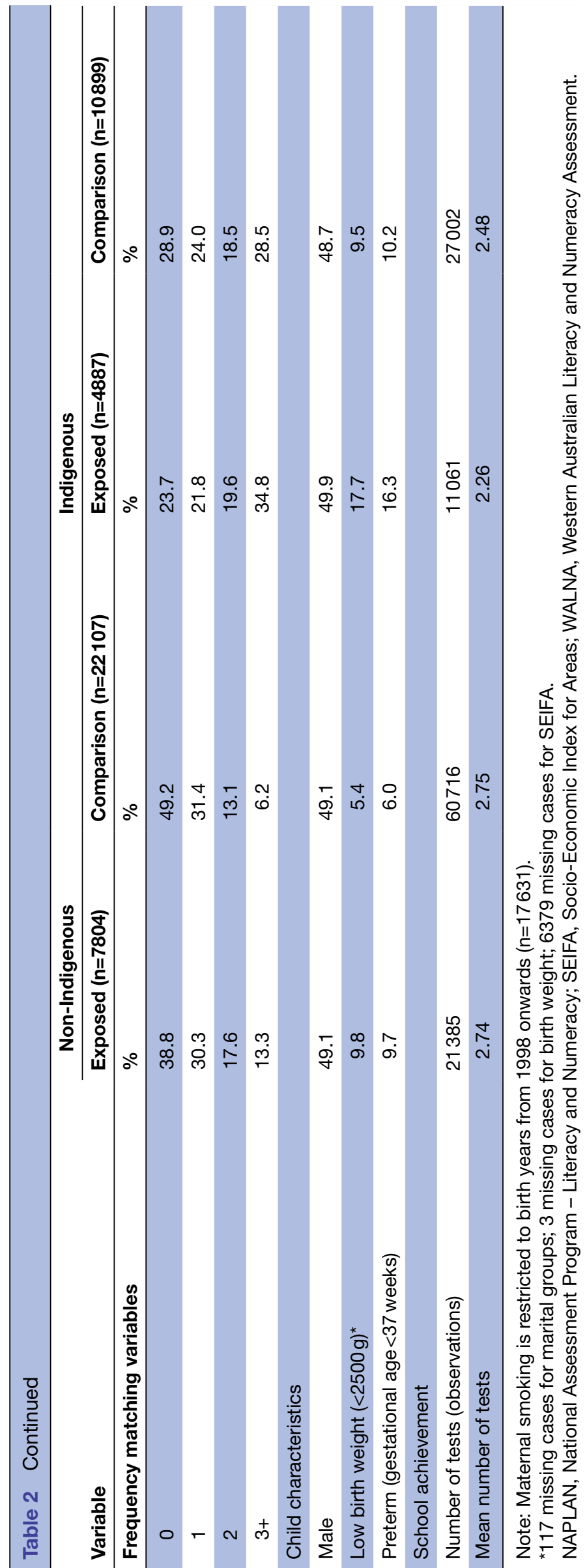


Table 3 Proportions not meeting WALNA and NAPLAN benchmarks and ORs of not reaching benchmark in the exposed versus comparison cohorts by Indigenous status and testing domain

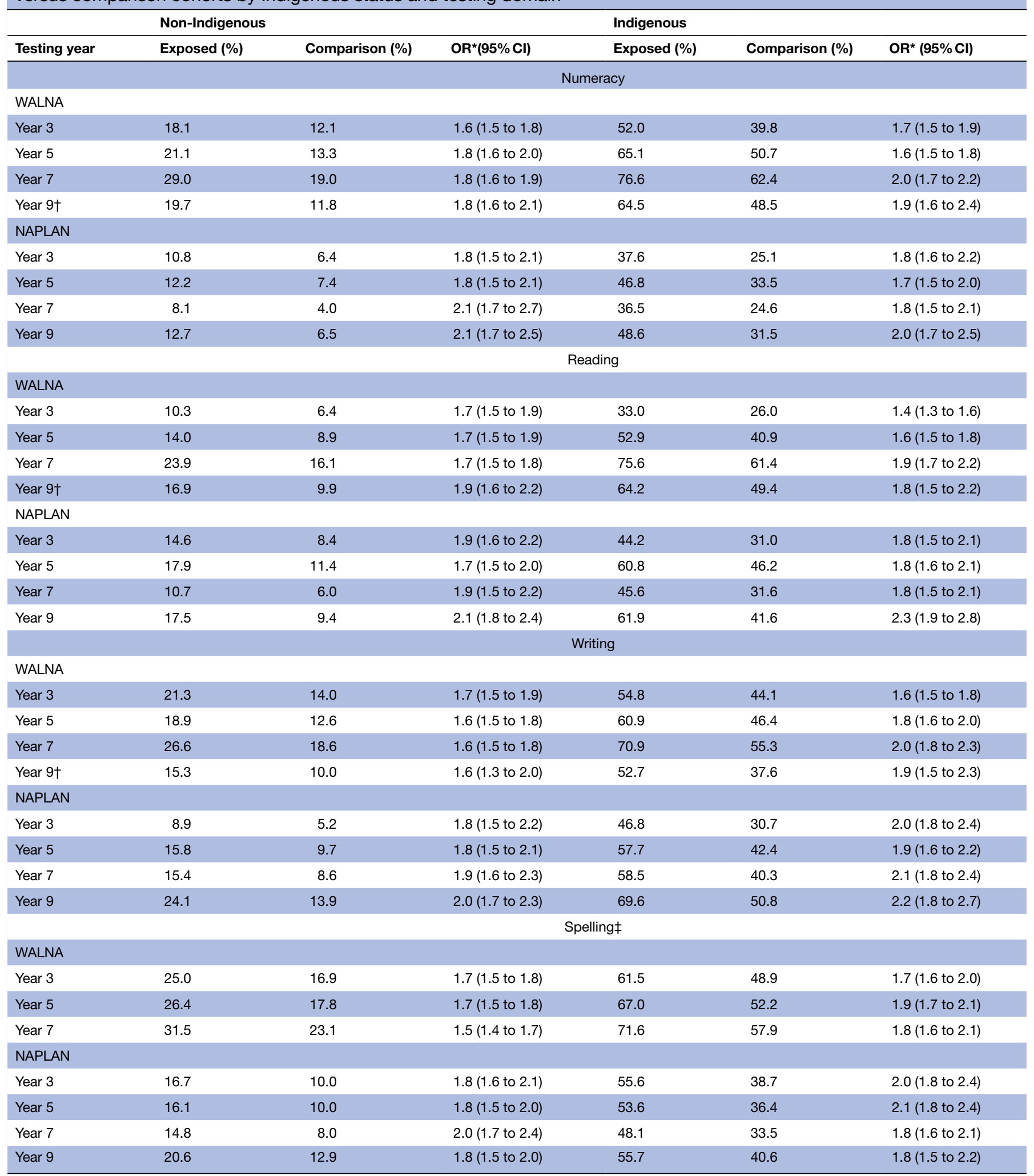

${ }^{*}$ Conditional analysis using logistic procedure adjusted for frequency matching variables maternal age and child's year of birth.

†Year 9 WALNA for 2004-2007 for numeracy and reading; from 2005 to 2007 for writing.

$\ddagger$ There were no spelling tests conducted under WALNA for Year 9 students.

NAPLAN, National Assessment Program - Literacy and Numeracy; WALNA, Western Australian Literacy and Numeracy Assessment. 
Table 4 Binary mixed model: aOR of not reaching NAPLAN or WALNA benchmarks by Indigenous status, testing domain and testing year

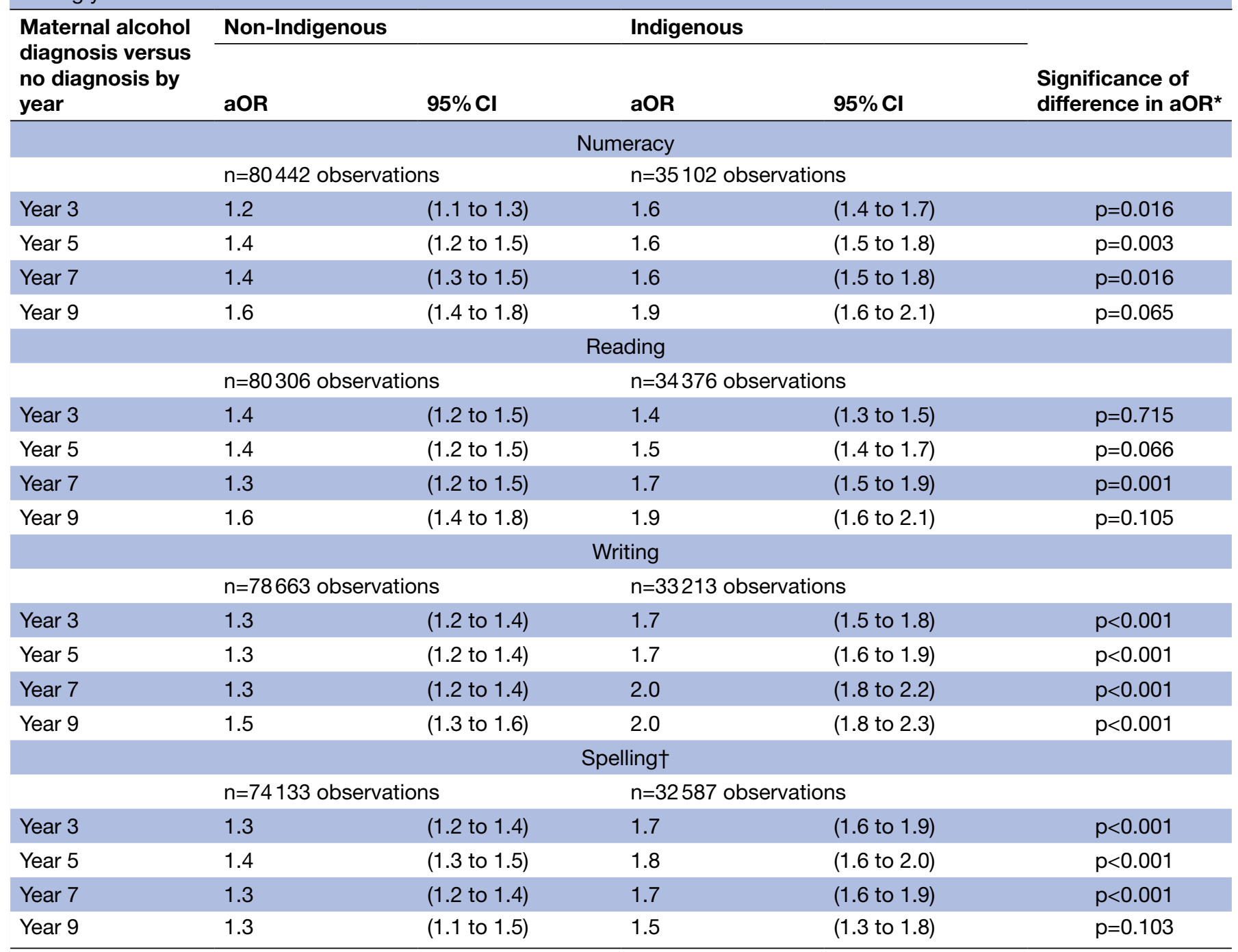

Notes: Results are adjusted for maternal age and year of birth (matching variables), child gender, low birth weight, preterm, gender, calendar year of test, maternal marital status, SEIFA, rural/metro place of residence, illicit drug use and mental disorder.

${ }^{*} p$ Value of difference in estimates between Indigenous and non-Indigenous cohorts.

†Spelling tests were only conducted in Year 9 under NAPLAN not WALNA.

aOR, adjusted OR; NAPLAN, National Assessment Program - Literacy and Numeracy; SEIFA, Socio-Economic Index for Areas; WALNA,

Western Australian Literacy and Numeracy.

maternal alcohol-related diagnosis (table 5). There were some differences between Indigenous and non-Indigenous children. When a maternal alcohol-related diagnosis was recorded during pregnancy, the odds of not reaching benchmarks across testing domains were higher for Indigenous children (aOR range: 2.0-2.4) than non-Indigenous children (aOR range: 1.4-1.6). These differences were statistically significant at $\mathrm{p}<0.05$ for writing and spelling. Likewise, these differences were significant when a maternal alcohol-related diagnosis was recorded more than 1 year prepregnancy, up to 1 year prepregnancy or 1 year postpregnancy.

\section{Sensitivity analysis}

Using the restricted data set, the odds of failure to reach benchmarks in the exposed versus comparison cohorts are modestly reduced with adjustment for smoking in some testing domains, but mostly still remain significant (see online supplementary table 2 ). The aORs that were not statistically significant (in particular, for Year 7 in numeracy, reading and spelling in the non-Indigenous group) were not significant in the models without and with adjustment for smoking status.

\section{DISCUSSION}

This is the first Australian population study to use linked administrative data to examine school achievement using standardised testing among children of mothers with an alcohol-related diagnosis.

The study found that children of mothers with an alcohol-related diagnosis were significantly more likely than 
Table 5 Binary mixed model: aOR of not reaching NAPLAN or WALNA benchmarks by timing of record of maternal alcohol diagnosis, Indigenous status and testing domain

\begin{tabular}{|c|c|c|c|c|c|}
\hline \multirow[b]{2}{*}{ Timing of record of diagnosis } & \multicolumn{2}{|c|}{ Non-Indigenous } & \multicolumn{2}{|c|}{ Indigenous } & \multirow{2}{*}{$\begin{array}{l}\text { Significance of } \\
\text { difference in aOR }\end{array}$} \\
\hline & aOR & $95 \% \mathrm{Cl}$ & aOR & $95 \% \mathrm{Cl}$ & \\
\hline \multicolumn{6}{|c|}{ Numeracy } \\
\hline & \multicolumn{2}{|c|}{$\mathrm{n}=80442$ observations } & \multicolumn{2}{|c|}{$\mathrm{n}=35102$ observations } & \\
\hline No alcohol diagnosis & 1.0 & & 1.0 & & \\
\hline GT 1 year prepregnancy & 1.4 & (1.3 to 1.6$)$ & 1.5 & (1.3 to 1.8$)$ & $p=0.449$ \\
\hline Up to 1 year prepregnancy & 1.4 & (1.1 to 1.6$)$ & 1.6 & (1.3 to 2.0$)$ & $p=0.195$ \\
\hline During pregnancy & 1.5 & (1.1 to 2.0$)$ & 2.1 & (1.7 to 2.5$)$ & $\mathrm{p}=0.081$ \\
\hline Up to 1 year postpregnancy & 1.5 & (1.2 to 2.0$)$ & 1.5 & (1.2 to 1.8$)$ & $\mathrm{p}=0.897$ \\
\hline \multirow{3}{*}{ GT 1 year postpregnancy } & 1.3 & (1.2 to 1.4$)$ & 1.6 & (1.5 to 1.8$)$ & $p<0.001$ \\
\hline & \multicolumn{4}{|c|}{ Reading } & \\
\hline & \multicolumn{2}{|c|}{$\mathrm{n}=80306$ observations } & \multicolumn{2}{|c|}{$\mathrm{n}=34376$ observations } & \\
\hline No alcohol diagnosis & 1.0 & & 1.0 & & \\
\hline GT 1 year prepregnancy & 1.4 & (1.3 to 1.6$)$ & 1.6 & (1.4 to 1.8$)$ & $p=0.219$ \\
\hline Up to 1 year prepregnancy & 1.3 & (1.1 to 1.6$)$ & 1.3 & (1.1 to 1.6$)$ & $p=0.913$ \\
\hline During pregnancy & 1.4 & (1.1 to 1.9$)$ & 2.0 & (1.6 to 2.3$)$ & $p=0.084$ \\
\hline Up to 1 year postpregnancy & 1.5 & (1.1 to 1.9$)$ & 1.8 & (1.5 to 2.3 ) & $p=0.268$ \\
\hline \multirow[t]{3}{*}{ GT 1 year postpregnancy } & 1.4 & (1.3 to 1.5$)$ & 1.5 & (1.4 to 1.6$)$ & $p=0.061$ \\
\hline & \multicolumn{4}{|c|}{ Writing } & \\
\hline & \multicolumn{2}{|c|}{$\mathrm{n}=78663$ observations } & \multicolumn{2}{|c|}{$\mathrm{n}=33213$ observations } & \\
\hline No alcohol diagnosis & 1.0 & & 1.0 & & \\
\hline GT 1 year prepregnancy & 1.4 & (1.3 to 1.6$)$ & 1.8 & (1.6 to 2.0$)$ & $p=0.007$ \\
\hline Up to 1 year prepregnancy & 1.4 & (1.1 to 1.7$)$ & 1.8 & (1.5 to 2.2$)$ & $p=0.041$ \\
\hline During pregnancy & 1.6 & (1.2 to 2.1$)$ & 2.4 & (1.9 to 2.9$)$ & $p=0.018$ \\
\hline Up to 1 year postpregnancy & 1.4 & (1.1 to 1.8$)$ & 1.8 & (1.4 to 2.3 ) & $\mathrm{p}=0.130$ \\
\hline \multirow[t]{3}{*}{ GT 1 year postpregnancy } & 1.3 & (1.2 to 1.4$)$ & 1.7 & (1.6 to 1.9$)$ & $\mathrm{p}<0.001$ \\
\hline & \multicolumn{4}{|c|}{ Spelling $†$} & \\
\hline & \multicolumn{2}{|c|}{$\mathrm{n}=74133$ observations } & \multicolumn{2}{|c|}{$\mathrm{n}=32587$ observations } & \\
\hline No alcohol diagnosis & 1.0 & & 1.0 & & \\
\hline GT 1 year prepregnancy & 1.5 & (1.3 to 1.6$)$ & 1.7 & (1.5 to 2.0$)$ & $\mathrm{p}=0.055$ \\
\hline Up to 1 year prepregnancy & 1.4 & (1.2 to 1.7$)$ & 2.1 & (1.7 to 2.6$)$ & $p=0.008$ \\
\hline During pregnancy & 1.4 & (1.1 to 1.9$)$ & 2.3 & (1.9 to 2.9$)$ & $p=0.007$ \\
\hline Up to 1 year postpregnancy & 1.5 & (1.1 to 1.9$)$ & 1.8 & (1.4 to 2.3$)$ & $p=0.238$ \\
\hline GT 1 year postpregnancy & 1.3 & (1.2 to 1.4$)$ & 1.6 & (1.5 to 1.8$)$ & $\mathrm{p}<0.001$ \\
\hline
\end{tabular}

Notes: Results are adjusted for maternal age and year of birth (matching variables), child gender, low birth weight, preterm, calendar year of test, testing year $(3,5,7,9)$, maternal marital status, SEIFA, rural/metro place of residence, illicit drug use and mental disorder; random intercept per child.

${ }^{*} \mathrm{p}$ Value of difference in estimates between Indigenous and non-Indigenous cohorts.

†Spelling tests were only conducted in Year 9 under NAPLAN not WALNA.

aOR, adjusted OR; NAPLAN, National Assessment Program - Literacy and Numeracy; SEIFA, Socio-Economic Index for Areas; WALNA,

Western Australian Literacy and Numeracy; GT, greater than.

comparison children to fail to reach national benchmarks on standardised numeracy and literacy tests. The proportions of children of mothers with an alcohol diagnosis not meeting benchmarks ranged from $8 \%$ to $31 \%$ of non-Indigenous students and from $33 \%$ to $76 \%$ of Indigenous children. This compares to national figures indicating that less than $10 \%$ of all non-Indigenous and up to a third of all Indigenous students fail to achieve educational benchmarks. ${ }^{1}$ With adjustment for confounders, the ORs for not achieving educational benchmarks were significantly higher among children of mothers with an alcohol diagnosis compared with comparison children for most tests (aOR range: 1.2-1.6 among non-Indigenous; aOR range: 1.4-2.0 among Indigenous children). It is possible 
that the confounding variables included were more appropriate for the non-Indigenous than the Indigenous children. Social inequalities in the health and well-being of Indigenous Australians compared with non-Indigenous Australians may be more influenced by social, historical and cultural factors, or be related to regional or community differences associated with the harmful use of alcohol, availability of interventions, quality of schooling and school attendance. ${ }^{27}{ }^{28}$ Furthermore, rates of harm associated with the use of alcohol among Indigenous Australians are much higher than for non-Indigenous Australians with negative impacts on child development, health and well-being. ${ }^{28}$

Overall the timing of the record of maternal alcohol diagnosis made little difference to the strength of association with school achievement. The detrimental effect of an alcohol-related diagnosis during pregnancy is consistent with previous studies that have mostly used measures of binge drinking. ${ }^{18-22}$ In the only other study with comparable benchmark data, O'Leary et alfound that higher proportions of children whose mothers reported to be drinking heavily in the first trimester of pregnancy failed to achieve benchmarks in reading, spelling and writing (but not numeracy) than children of mothers who abstained throughout pregnancy. ${ }^{20}$ In contrast to our findings, Alati and colleagues found no significant association between postnatal binge drinking by the mother or a partner and school achievement, thereby attributing findings to intrauterine mechanisms. ${ }^{18}$ Furthermore, a previous study using this cohort found that the risk of intellectual disability was highest when a maternal alcohol-related diagnosis was recorded during pregnancy. ${ }^{29}$ It is therefore difficult to determine what proportion of the association can be attributed to prenatal alcohol exposure and therefore FAS, and the proportion that may be due to unadjusted confounding factors such as low levels of maternal education, ${ }^{13}{ }^{20}$ unstable and overcrowded housing, ${ }^{1821}$ and problems with family, peers or at school. ${ }^{89}$ Another possible explanation is that women with alcohol-related diagnoses are likely to have persisting problems but no health service record of these during pregnancy.

A major strength of this study is the use of a population-based cohort of non-Indigenous and Indigenous mothers, and information about diagnosis that precedes the measures of educational outcomes. In addition, the exposed cohort (having an alcohol diagnosis) was identified based on standard ICD-9 and ICD-10 classifications, and educational outcomes are comparable with national and state benchmark data. Our results are therefore generalisable in the Australian context, and results for the non-Indigenous population are comparable in other populations that collect standardised school performance data, although similar studies in other settings may also reveal significant differences by ethnicity.

Loss to follow-up is unavoidable- $71.1 \%$ of the birth cohort linked to an achievement record partly because data were limited to public schools. Participation rates were also lower in the exposed versus the comparison cohorts, and especially among Indigenous children of mothers with an alcohol diagnosis. Another limitation is the definition of the cohort-these are serious alcohol use disorders and there will be women in the comparison cohort who may use alcohol at high levels, but have not had a hospital admission or contact with mental health or drug and alcohol services for it. The presence of FAS cases in the comparison cohort as previously described ${ }^{24}$ attests to this misclassification, which will lead to a bias in the measure of effect towards the null. Finally, as an observational study, it is likely that there are a number of residual confounding factors that we are unable to adjust for that may account for the greater risk of academic failure among children exposed to maternal alcohol disorders. These include factors associated with the family, school and neighbourhood environment, as well as other child development issues associated with alcohol exposure and cognitive development.

\section{Conclusions}

Altogether, 18486 children born between 1989 and 2007 in WA were identified as having a mother with an alcohol-related diagnosis (7515 Indigenous and 10971 non-Indigenous children). A high proportion of children of mothers with an alcohol-related diagnosis failed to meet minimum benchmarks, particularly Indigenous children. Identifying and addressing harmful maternal alcohol use in pregnancy and providing support to these mothers could improve educational outcomes of children. Furthermore, early identification and interventions aimed at targeting children exposed to maternal alcohol use disorder (and multiple risks) may improve longer term educational outcomes for these high-risk children.

Acknowledgements We thank the staff of the Western Australia (WA) Data Linkage Unit for access to the WA Data Linkage System and for their assistance in obtaining the data, and the WA Health and Education Data Custodians for access to the core data sets.

Contributors $\mathrm{CO}$ and CB conceptualised the study, obtained funding and arranged for data linkage along with JS and SRZ. NC and SEJ cleaned and coded the education data, undertook the analysis and drafted the manuscript. DL provided expert advice to the statistical analyses and contributed to the initial draft of the paper. All authors reviewed, revised and approved the final manuscript.

Funding The project is funded by an Australian Research Council Discovery Project (Project ID DP140101573).

Competing interests None declared.

Ethics approval Princess Margaret Hospital HREC, WA Department of Health HREC and WA Aboriginal Health Ethics Committee.

Provenance and peer review Not commissioned; externally peer reviewed.

Data sharing statement There is no additional unpublished data available from this study.

Open Access This is an Open Access article distributed in accordance with the Creative Commons Attribution Non Commercial (CC BY-NC 4.0) license, which permits others to distribute, remix, adapt, build upon this work non-commercially, and license their derivative works on different terms, provided the original work is properly cited and the use is non-commercial. See: http://creativecommons.org/ licenses/by-nc/4.0/

(C) Article author(s) (or their employer(s) unless otherwise stated in the text of the article) 2017. All rights reserved. No commercial use is permitted unless otherwise expressly granted. 


\section{REFERENCES}

1. National Education Reform Agreement. 2013 http://www. federalfinancialrelations.gov.au/content/npa/education/nationalagreement_201412.pdf (accessed 17 Aug 2016).

2. Australian Institute of Health and Welfare. A picture of Australia's Children 2012. Canberra: AlHW, 2012. http://www.aihw.gov.au/ publication-detail/?id=10737423343. (accessed 17 Aug 2016).

3. Forget-Dubois N, Lemelin J-P, Boivin M, et al. Predicting early school achievement with the EDI: a longitudinal Population-Based study. Early Educ Dev 2007;18:405-26.

4. Zubrick SR, Taylor CL, Lawrence D, et al. The development of human capability across the lifecourse: perspectives from childhood.. Australas Epidemiol 2009;16:6-10.

5. Flak AL, Su S, Bertrand J, et al. The association of mild, moderate, and binge prenatal alcohol exposure and child neuropsychological outcomes: a meta-analysis. Alcohol Clin Exp Res 2014;38:214-26.

6. O'Leary CM, Bower C. Guidelines for pregnancy: what's an acceptable risk, and how is the evidence (finally) shaping up? Drug Alcohol Rev 2012;31:170-83.

7. Vall O, Salat-Batlle J, Garcia-Algar O. Alcohol consumption during pregnancy and adverse neurodevelopmental outcomes. J Epidemiol Community Health 2015;69:927-9.

8. Burke S, Schmied V, Montrose M. Literature review: parental alcohol misuse and the impact on childen. Sydney: NSW Dept of Community Services, 2006.

9. Johnson JL, Leff M. Children of substance abusers: overview of research findings. Pediatrics 1999;103:1085-99.

10. Henderson J, Kesmodel U, Gray R. Systematic review of the fetal effects of prenatal binge-drinking. J Epidemiol Community Health 2007;61:1069-73.

11. Goldschmidt L, Richardson GA, Stoffer DS, et al. Prenatal alcohol exposure and academic achievement at age six: a nonlinear fit. Alcohol Clin Exp Res 1996;20:763-70.

12. Goldschmidt L, Richardson GA, Cornelius MD, et al. Prenatal marijuana and alcohol exposure and academic achievement at age 10. Neurotoxicol Teratol 2004;26:521-32.

13. O'Callaghan FV, O'Callaghan M, Najman JM, et al. Prenatal alcohol exposure and attention learning and intellectual ability at 14 years: a prospective longitudinal study. Early Hum Dev 2007;83:115-23.

14. Olson HC, Sampson PD, Barr H, et al. Prenatal exposure to alcohol and school problems in late childhood: a longitudinal prospective study. Dev Psychopathol 1992;4:341-59.

15. Olson HC, Streissguth AP, Sampson PD, et al. Association of prenatal alcohol exposure with behavioral and learning problems in early adolescence. J Am Acad Child Adolesc Psychiatry 1997;36:1187-94.

16. Streissguth AP, Barr HM, Sampson PD. Moderate prenatal alcohol exposure: effects on child IQ and learning problems at age $71 / 2$ years. Alcohol Clin Exp Res 1990;14:662-9.
17. Streissguth AP, Barr HM, Olson HC, et al. Drinking during pregnancy decreases word attack and arithmetic scores on standardized tests: adolescent data from a population-based prospective study. Alcohol Clin Exp Res 1994;18:248-54.

18. Alati R, Davey Smith G, Lewis SJ, et al. Effect of prenatal alcohol exposure on childhood academic outcomes: contrasting maternal and paternal associations in the ALSPAC study. PLOS One 2013;8:e74844.

19. Howell KK, Lynch ME, Platzman KA, et al. Prenatal alcohol exposure and ability, academic achievement, and school functioning in adolescence: a longitudinal follow-up. J Pediatr Psychol 2006;31:116-26.

20. O'Leary CM, Taylor C, Zubrick SR, et al. Prenatal alcohol exposure and educational achievement in children aged 8-9 years. Pediatrics 2013;132:e468-e475.

21. Sayal K, Heron J, Draper E, et al. Prenatal exposure to binge pattern of alcohol consumption: mental health and learning outcomes at age 11. Eur Child Adolesc Psychiatry 2014;23:891-9.

22. Zuccolo L, Lewis SJ, Smith GD, Davey Smith G, et al. Prenatal alcohol exposure and offspring cognition and school performance. A 'Mendelian randomization' natural experiment. Int $J$ Epidemiol 2013;42:1358-70.

23. Kilbey MM, Asghar K. Methodological issues in epidemiological, prevention, and treatment research on drug-exposed women and their children. Rockville, MD: US Department of Health and Human Services National Institute on Drug Abuse, 1992. https://archives. drugabuse.gov/pdf/monographs/117.pdf (accessed 17 Aug 2016).

24. O'Leary CM, Watson L, D'Antoine $\mathrm{H}$, et al. Heavy maternal alcohol consumption and cerebral palsy in the offspring. Dev Med Child Neurol 2012;54:224-30.

25. Australian Curriculum, Assessment and Reporting Authority 2012. NAPLAN achievement in reading, pursuasive writing, language conventions and numeracy: national report for 2012. Sydney: ACARA, 2012. http://www.nap.edu.au/_resources/NAPLAN_2012_ National_Report.pdf (accessed 17 Aug 2016).

26. Holman CD, Bass AJ, Rouse IL, et al. Population-based linkage of health records in WA: development of a linked database. Aust N Z J Public Health 1999;23:453-9.

27. Shepherd CC, Li J, Zubrick SR. Social gradients in the health of indigenous Australians. Am J Public Health 2012;102:107-17.

28. Wilson M, Stearne A, Gray D, et al. The harmful use of alcohol amongst indigenous Australians. 2010 http://www.healthinfonet.ecu. edu.au/uploads/docs/alcohol_review_june_2010.pdf (accessed 17 Aug 2016).

29. O'Leary C, Leonard H, Bourke J, et al. Intellectual disability: population-based estimates of the proportion attributable to maternal alcohol use disorder during pregnancy. Dev Med Child Neurol 2013;55:271-7. 